dents that one can neither maintain too high a pressure in the drive to prevent accidents nor can one exhaust the infinitely various list of possibilities of industrial mishap. This memorandum, recently issued by the Factory Department, is no brilliant exposition, but is a solid and sensible attempt to warn people of the commoner ways in which such poisoning may occur.

Statistics of accident and fatality due to $\mathrm{CO}$ for the years 1941-2-3 are given; these show that the annual incidence is fairly steady between 225 and 240 , while deaths undergo some variation between 5 and 10 per cent. of the incidence. It must be remembered that these cases refer to those which caused more than 3 days disablement and so reflect probably only a small fraction of those who have experienced symptoms from $\mathrm{CO}$. It would be of considerable interest to know at what levels of saturation workers find it necessary to stay off work for 3 or more days. It is significant that such noted investigators as Henderson and Haggard state emphatically that a claim for compensation should be rejected unless the claimant is exposed for at least 3 hours to conditions that could or did lead to 50 per cent. saturation of the blood, and was completely unconscious for at least 6 hours after return to fresh air. "Short of conditions of such severity,' they state, ' recovery is practically always complete' Such criteria mean, of course, that there is likely to result from such exposure irreversible lesions, probably in the central nervous system and brought about by the anoxaemia.

It seems generally agreed nowadays that the conception of chronic $\mathrm{CO}$ poisoning is fallacious. The memorandum under review states: "Carbon monoxide is not intrinsically a poison; it exercises its asphyxiant action not through any inherent toxicity in the carboxyhaemoglobin formed but simply through this power of using up most of the haemoglobin, which is the transporter of oxygen to the tissues.' As a physiological description of the action of $\mathrm{CO}$ this is very well but we suggest that it is unwise to talk of $\mathrm{CO}$ as 'not a poison' especially to a public not composed mainly of physiologists and in view of the sentence on the first page of the memorandum where it states: "poisoning by $\mathrm{CO}$ is the cause of between one-half and one-third of all reportable gassing accidents which occur in factories.'

It must be confessed that the industrial circumstances in which $\mathrm{CO}$ poisoning occurs are difficult to overcome especially where hand operations are in use, for example in manual charging of blast furnaces. Dependence on wind direction and ample space to avoid escape of gas seems poor comfort these days; the fact is that many of our plants are out of date and it is time we set our house or factories in order. The memorandum offers useful hints on how to minimize the hazards in various operations and instances safety rules drawn up by a steel-making firm for the instruction of workers. This is a valuable inclusion in a Government pamphlet. Instruction of workers in the dangers inherent in this work is not as universal as it ought to be. The various arguments adduced against this would all become irrelevant if intelligent co-operation were obtained between workers, their unions and employers.

In the description of the effects of various concentrations of $\mathrm{CO}$ the memorandum closely follows the work of Henderson and Haggard, but departs from them in recommending subcutaneous strychnine or pituitary extract as of great value in serious cases. These authorities, with whom we agree, condemn all hypodermic, intravenous and intracardiac medications as not only valueless but even harmful in the field. The great thing in treatment of a serious case is to re-establish respiration at the earliest moment by the Schäefer method, assure an adequate intake of $\mathrm{O}_{2}$ and $\mathrm{CO}_{2}$, and combat shock. The memorandum rightly stresses that the first few seconds may determine everything and save life.

In the matter of methods of detection and estimation of carbon monoxide in the atmosphere, it could have been helpful if a short critical review could have been included of the various methods recommended. For our part the only reasonable method is a continuous recorder, as otherwise the usual sequence will be calamity followed by determination of concentrations. M. W. G.

\section{OUTLINES OF PHYSICAL METHODS IN MEDICINE}

By G. D. Kersley, M.D., F.R.C.P.

(William Heinemann, London. 1945. Pp. 85. 6s.)

Physical medicine is a curious and rather illogical division of medicine, and when it goes beyond the normal group of treatment, massage, electro-, helio- and hydrotherapy, and includes occupational therapy, it is more illogical still. The author is right when he says that the abysmal ignorance and consequential lack of interest of many of the medical profession in physical medicine invited exploitation by the charlatan and provided little encouragement to those legitimately and conscientiously applying these matters. Doubtless the concept of rehabilitation will right these wrongs. No physician or surgeon can regard the treatment of his patient as complete until that patient is satisfactorily reemployed and this will undoubtedly require new methods. It would be better that the orthopaedic surgeon and the specialist in rheumatic diseases each controlled his own treatment; this is so in other countries. However, if the division of physical medicine is persisted with in England, then the closest liaison must be established with other branches of medicine. This little book, which gives an elementary account of the methods of physical medicine, is greatly to be welcomed at the present time and will enable the medical student and practitioner to acquire a knowledge of the subject.

K. M. A. P.

\section{A GUIDE TO HEATING, VENTILATION AND LIGHTING}

By W. Douglas Seymour

(Oxford University Press, London, New York and Toronto. 1944. Pp. 90. 6s.)

The author of this short book sets out to explain heating and ventilation in terms which will be understood by ' ordinary people, who by profession are probably baker, banker or billiard-marker.' But he does not fully succeed in his purpose, because, unconsciously, his language rapidly becomes technical, for example where he discusses methods of measuring temperature or the significance of daylight lighting. However, the potential misfortune of the billiard-marker is undoubtedly the fortune of the industrial medical officer. The book is at once short, clear, comprehensive, and inexpensive, and is one therefore that can be confidently commended to doctors employed in industry, not as a volume for permanent reference but as an effective introduction to a complex subject. The book is divided into two main parts: heating and ventilation, and lighting. The effect of these phenomena on our ability to work is explained in simple terms. If conditions are made comfortable at the place of work - the ultimate aim of heating, ventilation, and lighting - then productive effort is not interfered with, so there is mutual benefit to all parties. The author asks himself the question" Why are heating and ventilation necessary?" and gives the answer in simple physiological terms. This leads to chapters on old and new ideas; measurements of temperature; room comfort; and some description of modern methods of heating and ventilating. Similarly, the answer to the question "Why do we need light?" supplies the material for the second half of the book. Vision is possible only where there is light, so here is an immediate relationship between medicine and engineering. This link for the industrial medical officer is one of paramount importance; the more he knows about the material working environment the better can he apply his clinical knowledge. It is no doubt selfish to suggest that the book would have been improved, from our point of view, by more adequate references and by the provision of an index. 